\title{
El vértigo de la filosofía
}

\section{Crescenciano Grave}

\author{
No permaneces ya cautivo \\ en la sombra de las tinieblas, \\ y un nuevo anhelo te arrebata \\ hacia un enlace más alto \\ $Y$ mientras no poseas \\ ese imuere y sigue siendo!
} No serás más que un huésped sombrio sobre la tierra a oscuras.

Goethe

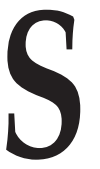

i todavía es lícito hablar de la vocación de pensar es porque ésta promueve la libertad en las distintas formas posibles de responderla. En la filosofía, una de las formas posibles de atender la vocación de pensar es aquella que se configura discursivamente aventurándose en el gran océano del devenir. En éste el cielo siempre está bajo y los relámpagos surcan la noche. Y ahí, en el latigazo de luz con la que hienden la oscuridad, permiten vislumbrar el fundamento en falta y la finalidad sin fin a los que refiere la presencia en devenir.

La filosofía de Eugenio Trías es una potente respuesta a la vocación de pensar escuchando los requerimientos del devenir. En el desarrollo de la obra del pensador español, Filosofía del futuro (1983) ocupa un lugar clave para ahondar en su propuesta. Esto por dos razones: en primer lugar, el libro mencionado es el primero de una trilogía (completada por Los límites del mundo de 1985 y La aventura filosófica de 1988) en la que se lleva a cabo el recorrido metódico que desemboca en la idea de la filosofía del límite, de tal modo que, en segundo lugar, tenemos aquí el germen de su pensamiento sobre el ser como límite dentro del cual deviene lo que aparece remitiendo, a la vez, al enigma de lo encerrado en sí. Sin embargo, esta posición peculiar dentro de la trayectoria de su autor no nos debe ocultar que, como todo libro de valía, Filosofía del futuro tiene un interés por sí mismo. En efecto, aquí, Trías desarrolla la idea de que aquello que nos fuerza a pensar es la presencia del singular sensible en devenir y que a esta presencia se corresponde subjetivamente con el pathos del vértigo.

Sustentándonos, aunque no exclusivamente, en Filosofía del futuro, realizamos aquí un comentario a la ontología del devenir de Trías con la pretensión 
de recrearla como una forma trágica de pensamiento. Este comentario procura ser un ensayo filosófico, esto es, asumir la forma del pensamiento conceptual sin renunciar al gesto artístico de promover, desde las ideas, posibilidades afirmativas de la vida. El devenir que fuerza al pensar no lo constriñe categóricamente; inundándolo de pasión lo surte del contenido que recreado en el mismo pensamiento fomente la afirmación de la vida como aquello que, por su propio devenir y más allá de la extinción de los individuos, se renueva.

\section{Una ocupación inhóspita}

Pensar a la realidad como acontecimiento de la presencia, destacando en este acontecer no tanto la dimensión presente del tiempo como la futura, lleva a que la realidad misma se muestre como revelación de un fundamento que no se agota en su manifestación, puesto que él mismo ad-viene en la presencia abriendo el horizonte futuro en el cual el propio presente se sostiene como posibilidad de reiterarse. Y la posible renovación que se abre hacia delante del presente muestra también que éste es una insistencia de lo que hacia atrás ha quedado como pasado. Deviniendo, el presente se descubre como efectiva repetición del pasado y como posibilidad de repetirse en el futuro. Y en esta asunción del devenir, la filosofía se confronta no sólo con lo que hay y se da sino también con aquello que, ausente en tanto tal, puede recrearse y variarse a sí mismo dispersándose en la singularidad.

La filosofía es, hoy y siempre, reflexión sobre el presente, conceptuación del presente [...] El presente [...] es [...] presencia, parousía, revelación [...] de un fundamento en falta que se escamotea al mostrarse ahí, que adviene y abre un horizonte, futuro, desde el cual se funda el presente como reiteración, repetición de lo que es sido". ${ }^{1}$

La presencia del ser sensible en devenir revela, desde la apertura del futuro, un fundamento en falta. Ateniéndose a lo que hay y se da -la presencia- el pensamiento no se circunscribe a su constatación sino que abre su experiencia a la confrontación con lo que el mismo devenir expresa y a lo que él mismo remite: el fundamento (¿futuro?) que por su continuo advenir posibilita la presencia sin reducirse a ella.

Esta experiencia inunda de asombro al pensamiento que, transformándolo en interrogación sobre el devenir de la presencia y lo que, ausente, se revela en ella, se encuentra desasido de todo cimiento en tierra firme. Abriéndose al

\footnotetext{
${ }^{1}$ Eugenio Trías,. Filosofía del futuro. Barcelona, Destino, 1995, p. 11.
} 
devenir y a la singularización de la presencia múltiple, el pensamiento, en tanto asombro convertido en interrogación, se descubre sustentado en un estado de ánimo peculiar: el vértigo. Al formular las preguntas específicamente filosóficas el pensador se ve arrasado y desfondado por el vértigo que se le impone. No se cuestiona por el singular sensible en devenir y su fundamento en falta desde una serenidad ajena a la conmoción de la presencia misma: asaltado por el radical devenir de lo singular el sujeto del pensar se ve arrobado por el pathos del vértigo desde donde se plantea el interrogante último. El vértigo es la correspondencia anímica y, por tanto, subjetiva del fluir de la presencia y su constante reiteración. En el desfondamiento vertiginoso del pensar, la presencia en devenir se interroga remitiendo a su falta: el vértigo del pensador replica al devenir que, como advenimiento, refiere a su fundamento en falta.

Vértigo, visión del abismo sin fondo, sensación de perder pie, resquebrajamiento de todo lo que es firme, el suelo que piso, la tierra en donde me cobijo, pérdida de toda certidumbre en donde alojar algún convencimiento, pérdida de todo aquello en donde pueda reposar mis angustias, mis interrogaciones sin respuesta: he aquí el suelo, la tierra, el espacio paradójico en donde precaria y desasosegadamente se instala una ocupación inhóspita: la filosofía. ${ }^{2}$

Desasido de todo cimiento en tierra firme, el pensar filosófico no se hunde en la nada; se abisma en el devenir y desde el devenir mismo afirma y levanta sus potencias creadoras. En el vértigo el filósofo queda suspendido; pero esta suspensión no es reposo sino la máxima tensión a la que lo someten dos convocatorias igualmente exigentes: la llamada a perseverar en el ser en devenir y la atracción por disolverse en el pozo sin fondo de la nada. Sumida en este pathos, la filosofía -aquella que no renuncia al laberinto a que sus propias interrogaciones la condenan pero tampoco se solaza en el extravío que pasa de todo-, se reitera y recrea de tal modo que, inspirándose en la condición transitoria de todo lo que se presenta, no se desbarranca en el nihilismo sino que se levanta trágicamente.

¿Cómo desde el vértigo se abre la posibilidad de asumir trágicamente al logos? ¿Cómo este logos trágico es una reafirmación radical de la metafísica? El vértigo es la pasión filosófica que se experimenta como una lucha en el interior del propio sujeto del pensamiento entre la vocación a perseverar en el ser individual, finito, limitado, y la tendencia a fundirse con el principio matricial -fundamento en falta- de todo ser. En el vértigo, la voluntad de pensar se forja resistiendo la atracción de fondo insondable de lo ilimitado y,

${ }^{2}$ Ibid., pp. 25-26. 
sin negarlo, lo desafía alzándose como filosofía afirmativa de y en el devenir. Sus-pendiéndolo entre dos deseos, el vértigo no paraliza al sujeto sino que, al afirmar sus dos tendencias en pugna, lo dispone a confrontarlas y cultivarlas en el pensamiento. Y la confrontación patentiza el señalamiento provocante del propio sujeto tanto en el ser como en la nada, es decir, en la doble y radical determinación que compone el devenir. ${ }^{3}$ El vértigo es el registro emocional de la raíz ontológica del devenir y, al profundizar en el suelo en el que la raíz misma se asienta, ésta se oculta en una oscuridad recóndita herida por algunos resquicios que liberan la claridad del ser en devenir. "Ese abismo sin fondo es el lugar que se mira cuando en verdad se filosofa, eso es lo que se admira cuando se produce la disposición que hace posible la filosofía [...] Tiene por objeto el devenir, que es ser agujereado de no ser y es una nada generadora de ser". ${ }^{4}$

Resquebrajando la ilusión de un fundamento estable desde el cual se sostenga la totalidad sometida sólo a la legalidad y el cálculo, la propia totalidad aparece como dispersión de entes sensibles en devenir. Y al encarar este devenir en el vértigo que él mismo propicia se quiebra también toda certeza, toda presunción de asir regularmente la presencia advenida. Estos resquebrajamiento y quiebre, sin embargo, no sustraen la pasión del pensamiento; le dan un tono elevado produciendo en el propio sujeto el vértigo y el asombro cuestionante ante lo que deviene desde el abismo: el sujeto que filosofa en y desde el vértigo se abre en el asombro al devenir a la vez que pone en juego el pensamiento sustentado en el pathos que emocionalmente lo antecede. "Todo verdadero asombro viene acompañado de vértigo, es la posición de la atención -del logos- que corresponde al vértigo como posición emotiva y patética". ${ }^{5}$ Desde el atisbo fascinado - atraído y repelido a la vez- del fundamento en falta se pierde toda certidumbre y todo reposo y el registro emocional y racional de esta pérdida es el que impulsa a la actividad filosófica a seguir ocupándose de las preguntas radicales.

Al suspenderse toda certidumbre, al agrietarse el suelo firme de todo posicionamiento absoluto, el sujeto experimenta anímicamente el vértigo que, asombrando la atención al devenir, posibilita el despunte del sentido interrogativo de la razón. La razón -recuperando sus orígenes en el thauma platónico- se reconoce precariamente sustentada en el fondo pasional del asombro y del vértigo y desde allí no renuncia ni cancela su vocación por pensar radicalmente sino que afirma su disposición a la metafísica -el descenso hacia aquello que, por mantenerse en el fondo, se escabulle a toda determinación

\footnotetext{
${ }^{3}$ Cf. ibid., p. 28.

${ }^{4}$ Ibid., p. 29.

${ }^{5}$ Ibid., p. 28.
} 
definitiva- confrontándose con el fundamento en falta que se revela en la discontinuidad de la singularidad sensible que se presenta en devenir.

\section{Las condiciones de la filosofía}

La discontinuidad del devenir con relación a un fundamento en falta y su correspondiente suscitar vértigo en el ánimo, asombro en la atención y formulación de interrogantes lingüísticos en la razón son condiciones y disposiciones necesarias para el despliegue efectivo de la filosofía. Condiciones necesarias pero no suficientes; el alzado efectivo de la obra filosófica añade un extra a las anteriores condiciones y disposiciones: la filosofía prolonga al vértigo confrontándose trágicamente con lo que, birlándose a toda presencia, se revela en ella; al asombro en la atención lo continúa en la exclamación poética -formulación lingüística en la que se le crea una expresión- capaz de desvelar un ente sensible, singular, temporal, finito; y, por último, a la interrogación racional la completa con la formulación de una Idea en la cual se pretenda dar respuesta articulada, pero consciente de su problematicidad, a las preguntas formuladas. Respondiendo al acontecimiento físico del ser, a su devenir ocurriendo en entes sensibles singulares, temporales y finitos, "se trama la filosofía como proceso temporal, plegado a la temporalidad desplegada del devenir", y, en este mismo tramarse, el vértigo, el asombro y la interrogación trascienden su aislamiento fortuito y, por repetición, se inscriben como auténticos caracteres en los hábitos del pensador. ${ }^{6}$

Las pasiones vertiginosa y admirativa y la formulación lógico lingüística de interrogaciones radicales no son irrupciones pasajeras e inconstantes; son momentos excepcionales en la vida de un pensador que, en tanto tal, se las ingenia para repetir la experiencia. En la repetición la experiencia vuelve y se recrea constituyéndose en hábitos que se posesionan del alma de aquel que las adquiere. En este sentido, el vértigo, el asombro y el preguntar son condiciones constitutivas de la filosofía porque, al reiterarse, forman hábitos que se inscriben, como auténticos caracteres, en el ethos del pensador.

El destino de un pensador se forja desde la reiteración de sus hábitos. "Cuando el hábito es anímico es pasión; cuando el hábito es atentivo y lógico lingüístico es razón. La filosofía tiene por condición necesaria hábitos pasionales y racionales". ${ }^{7} \mathrm{Y}$, frente a toda comprensión plana, estos hábitos no conducen a la monotonía ni, mucho menos, al aburrimiento: la adquisición y posesión de estos hábitos filosóficos se logra sólo en la medida en que se los ex-

\footnotetext{
${ }^{6}$ Cf. ibid., pp. 30-31.
}

${ }^{7}$ Ibid., p. 31. 
perimenta y practica afrontando las preguntas radicales en una respuesta que, consciente de sus derivas temporales, se asume como problemática. Más que definitiva, la respuesta filosófica es siempre una propuesta que patentiza su potencia en la resucitación de nuevos cuestionamientos. Correspondiendo al devenir la respuesta filosófica recobra el pasado del pensamiento en una propuesta del presente abierta a su recreación futura. La respuesta filosófica reinterpreta propuestas anteriores que, no por debilidad sino por potencia, muestran su carácter crítico al confrontarlas con la propia experiencia y su asunción vertiginosa desde la fisura en la revelación del devenir mismo, y la presente respuesta filosófica muestra su carácter racional si alberga en sí misma su cuestionamiento crítico y, por lo tanto, no anula el resurgimiento del preguntar radical y la posibilidad de nuevas formulaciones de respuesta.

La disposición pasional y la formulación de interrogantes radicales potencian su disposición al ser filosóficamente respondidas en obras que posibilitan la convalidación crítica de su propia propuesta. La forma en que Trías despliega la filosofía aloja las disposiciones pasionales y lógicas convertidas en hábitos desde los que vuelve una y otra vez a las interrogantes sobre lo mismo y, nutriéndose de y recreando a respuestas anteriores, levanta su propia respuesta en la que se trama delicada y sutilmente y, a la vez, grandiosa y tremendamente, la formulación de la idea que la dirige. Y la idea que se descubre y despliega en Filosofía del futuro -como auténtico germen del futuro de esta misma filosofía- es el principio de variación. Concibiendo a la filosofía como una alteración constante sobre un único tema que, a su vez, se plantea en una serie de preguntas que siendo las mismas exigen respuestas variables, Trías encuentra ${ }^{8}$ en esa diversificación la palanca para sostener el principio de variación como idea en la cual se sintetizan dinámicamente mismidad y diferencia, unidad y diversidad, universal y singular.

\section{El principio de variación}

El punto de partida de la filosofía despunta al atenerse e insistir en el fenómeno presente en el tiempo catapultado desde un fundamento en falta. Este inicio, planteado subjetivamente, radica en el pathos de vértigo asombrado que, dicho objetivamente, se corresponde con la presencia en devenir del ente singular sensible. En el punto de partida no sólo se suspende toda tierra firme en la que el sujeto pueda arraigar sus certezas; también el ser en devenir, al mostrar su naturaleza finita, borra todo presunto sentido constituyente del devenir mostrando de forma problemática su ser. Al asumir el devenir en tanto tal el

${ }^{8}$ Cf. ibid., pp. 14 y 34. 
fondo del mismo se abisma patentizando su falta en el ser sensible y, a la vez, se cancela todo sentido trascendente que, como finalidad, lo someta y lo dirija. Esta doble suspensión reveladora de finitud en el ser y fragilidad en el conocer no paraliza al que la experimenta sino que, de-pendiendo peligrosamente de lo que en ella se muestra, lo impulsa a la interrogación radical. El vértigo en el ánimo y el asombro en la atención urden el cuestionar desde donde el logos (pensar-decir) se tejerá como respuesta filosófica.

¿Qué es propiamente lo que, deviniendo, se presenta? ¿Desde dónde emerge esa misma presencia? ¿Hacia dónde se dirige esa presencia que, sumergiéndose en el horizonte del tiempo, desaparece? Al preguntarse por el fundamento y la finalidad del devenir estos mismos se pliegan en la interioridad del logos (que, no olvidemos, está inseminado de vértigo y asombro) desde donde brotan como fundamento en falta y finalidad sin fin. En el principio mismo de la respuesta filosófica ésta, dispuesta por el vértigo y el asombro, evita la tentación de volver a caer en las respuestas meta-físicas de un arkhé y un telos que, trascendentemente iguales, sujeten y conduzcan de manera inconmovible al devenir.

Pensar al devenir desde el fundamento en falta y en referencia a la finalidad sin fin no hunde a la filosofía en la inanidad, ya que el pensador, resuelto en el mismo devenir, da la vuelta de tuerca por la cual la presencia es afirmada más que como mera irrupción y desaparición entre la nada que la antecede y la sucede: en la transformación lingüística y racional del pathos vertiginoso y admirativo se descubre que, en tanto en devenir, el ser sensible no sólo deja ver su fragilidad, también proyecta su poder; el ser mismo responde a su propia naturaleza problemática en el mismo devenir puesto que éste posibilita no sólo la aparición y la desaparición sino también la insistencia y la revalidación del ser en la recreación. "La idea de recreación permite explicitar el horizonte de ser y nada que constituye el devenir". 9 Lo singular en devenir y la recreación, más que la aniquilación, se constituyen en los dos hilos con los cuales se trama el principio de variación.

¿Qué es propiamente lo singular? En tanto pensador que no niega sino que pretende cultivar las virtudes filosóficas de su propia lengua, Trías no se esconde tras neologismos espantadores de ideas; él recurre a la significación normal de ciertos términos para recrearlos acogiéndolos en su propio tramado filosófico. Singular en castellano posee una significación cuantitativa y otra cualitativa. Esta última opera cuando nos referimos a algo que destaca sorprendiéndonos y despertando nuestra curiosidad. Intensificando esta significación cualitativa podemos hablar de algo "muy singular" para referirnos a un ente cuya radical mismidad es su propio carácter extraño e insistente en presentarse.

${ }^{9}$ Ibid., p. 47. 
Amparándose en el genio de su propia lengua, Trías formula su idea de lo singular propio como aquello que puede determinarse en razón de su recurrencia en el tiempo de ciertas propiedades o rasgos trabados que porfían en presentarse, constituyéndolo, en un ente cualquiera. Al singular propio no se le ata a una esencia previa que, determinándolo, se exprese fenoménicamente en él; es la misma recurrencia temporal y fenoménica del singular propio lo que permite determinar su constitución estructural: es el propio fenómeno singular el que deja formar su idea como esencia en el tiempo expresando su consistencia bajo un estilo distintivo. El estilo es la expresión del ser no como esencia general sino como esencia que se potencia en lo singular manifestándose tal y como es.

La singularidad del ser radica en su poder de recrearse a sí mismo; y este poder es su esencia no como constitución fija sino como un constituirse insistiendo en revalidarse frente al horizonte de no ser en que se juegan sus propias posibilidades de recreación. En sus propias finitud y singularidad el ser muestra su naturaleza problemática.

En una palabra, su ser en devenir: su reiteración en otro ser que es el mismo siendo diferente, siempre el mismo siempre diferente. El singular es, pues, por razón de su singularidad probada por las recreaciones, inmediatamente universal. Es a la vez lo mismo (uno) a través de sus diversificaciones (universal). ${ }^{10}$

En la recreación el ser repite lo que ha sido volviendo a ser diferentemente. Y el valor de un ser se mide cualitativamente por su capacidad de re-crearse. Este poder posee una raíz física desde la cual deriva su potencia lógica: insistiendo en su repetición distinta, el ser sensible en devenir se revela como síntesis de singularidad y universalidad, síntesis que, a la vez, permite pensarlo como aquello que sólo en su diversificación mantiene su mismidad. La raíz física del poder que se manifiesta en la recreación de lo mismo en lo diferente llevada a su potencia lógica como síntesis de lo universal y lo singular es lo que Trías llama el principio de variación que, en tanto razón o logos, es lo que sostiene dicha síntesis. Y el puntal de este sostenimiento no se localiza en una lógica abstracta; se pude hablar de lo singular diciendo propiamente algo apuntalándolo en lo físico: la posibilidad de pensar, hablar y razonar es una posibilidad sostenida en la física, en la naturaleza que, como materia de inteligencia y pasión, deviene hombre. El poder hablar racionalmente sobre el ser en devenir es una posibilidad que se realiza sustentándose en la capacidad re-creativa del mismo ser que se diferencia y potencia produciéndose como ente dotado de logos.

${ }^{10}$ Ibid., p. 49. 
El poder físico del ser, su posibilidad de recreación, es lo que le permite ser lo mismo siempre variándose. Llevando a su máxima tensión filosófica la inspiración musical del principio de variación - el tema es el que se rehace y recrea en cada variación y ésta es más genuina cuanto más consiga, desde la desviación y la memoria, singularizarlo y diferenciarlo- ${ }^{11}$ Trías piensa al ser sensible en devenir como aquel que, singularizándose, extrema su poder en la reiteración diferente de sí mismo. No hay un ser aparte y trascendente a sus variaciones; en tanto ser en devenir se mantiene como el mismo en la diversificación de los entes singulares. El principio de variación articula la concepción del ser como poder y la comprensión de éste no sólo como dominio sino, sobre todo, como insistencia recreadora de sí mismo que alcanza sus mayores cuotas en aquellas variaciones que más lo diferencian singularizándolo. Y el devenir del ser sensible recreándose singularmente se des-prende de un fundamento en falta de-pendiendo de su propia referencia a una finalidad sin fin.

\section{Viaje dramático y viaje trágico}

Pensar al ser sensible en devenir como ad-viniendo desde un fundamento en falta y en referencia a una finalidad sin fin es, en cierto sentido y a nuestro parecer, una radicalización ontológica de una incursión anterior sobre el drama y la tragedia llevada a cabo por Eugenio Trías en Drama e identidad (1974).

Drama y tragedia constituyen ejemplos literarios que proporcionan elementos para reflexionar diversos tipos de sensibilidad, de erotismo, e incluso, de pensamiento, esto es, de una lógica dramática y una lógica trágica. Esta reflexión es surtida por los distintos modos de viaje que los personajes experimentan en el drama y en la tragedia.

El viaje dramático se aventura por tierra extraña, pero de tal modo que nunca se desvanecen las señales que, recuperándolas o descifrándolas, permiten retomar el sendero desde donde se vuelve posible el retorno al hogar o el arribo al puerto de redención y de reconocimiento. Mediante una serie de decisiones que lo definen y encaminan al desenlace, el viajero encontrará la resolución de su propia identidad cumplida. El drama se ensambla al tiempo y en éste acontece el proceso por el cual, a través de las mediaciones que desatan una serie de transformaciones, el sujeto logra deshacerse de todo embozamiento y consigue la verdad de su identidad plena.

El viaje trágico es, en cambio, un extravío en el cual se pierden todas las señales que permitirían el regreso a casa. Y, con esta pérdida, se desvanece también toda esperanza de satisfacción y felicidad. Este desvanecimiento ocurre, paradójicamente, porque el hombre trágico no quiere renunciar a nada

${ }^{11}$ Cf. ibid., p. 55. 
y, por esto, no se decide, ni tampoco se determina de tal modo que él es el extravío. La tragedia se escenifica en el infierno sin alternativa de purgatorio ni, mucho menos, de paraíso prometido. "El infierno es la excesiva lucidez e inteligencia". ${ }^{12}$ La luz en demasía condena al que la padece a las tinieblas de la contradicción: por no querer renunciar a nada se le escapa todo. La tragedia, al negar toda acción definitiva, imposibilita la redención. El extravío trágico, por carecer de desenlace salvífico, se consolida en el tiempo que a su vez no discurre como un proceso que llevará a costas reconfortantes sino que pareciera enquistarse como un fragmento de eternidad desolada.

La modalidad de viaje y viajero dramáticos implica una pérdida del hogar y, a pesar de los pesares, una recuperación del camino recto que permitirá construir un proceso resolutivo. En cambio, la modalidad de viaje y viajero trágico es un completo extravío en el cual se carece de punto de partida y de meta; la existencia irrumpe aquí sin principio y sin finalidad; sin ningún centro de referencia que permita albergar la esperanza de que alguna vez estaremos en el mundo como en casa. Esta tragedia de la ausencia y la desolación es la que, de acuerdo con Trías, pertenece a nuestra sociedad y su cultura y los testigos que la llevan a la palabra, entre otros, son Joyce, Kafka y Beckett. ${ }^{13}$

Sin principio que la fundamente y sin finalidad que la oriente, la existencia trágica contemporánea carece irremediablemente de la ilusión de, apoyándose en sí misma, decidirse y resolver su identidad. En el naufragio sin nada a qué aferrarse, en la supresión de la voluntad por la cual el cosmos inunda la conciencia como verdadera nada, en la burla cruel a la que el azar somete al que queriendo tocar la profundidad no alcanza nada y en nada se hunde, los viajeros trágicos "enmascaran ni más ni menos esa nada. Tapan con su embozamiento la ausencia de identidad, el agujero por el que nombre e identidad se hunden en el vacío del abismo". ${ }^{14}$

Viaje como extravío sin origen y sin final, viajero sin acción definitoria que le permita trazar un desenlace son las notas distintivas de un concepto de tragedia en el cual la vida plasmada por Schopenhauer parece haber sido retocada con tremendo estilo por algunos de los puntales de la literatura contemporánea. No obstante, y a pesar de reconocer la lucidez infernal que brilla en el yermo, Trías no sacrifica su pensamiento en el nihilismo. Más bien se las ingenia para resarcir la idea de tragedia buscando en la misma crisis de nuestra cultura y su pasado huellas de la idea-fuerza en la que "vibra aún, de un modo trágico, el nervio de la metafísica". ${ }^{15}$ Y es que si, desde Schopenhauer,

\footnotetext{
12 E. Trías, Drama e identidad. Barcelona, Barral Editores, 1974, p. 132.

${ }^{13}$ Cf. ibid., p. 90.

${ }^{14}$ Ibid., p. 89.

15 Ibid., p. 72.
} 
la tragedia se derrumba en la nada, desde Kierkegaard y Nietzsche es posible poner a prueba una reflexión que alumbre una metafísica trágica que afirme el devenir y, en éste, convalide la existencia singular.

\section{Poder y variación}

El viaje trágico presenta, a manera de concentrado o precipitado, al devenir como una irrupción en la que no hay principio último ni fin final. Ese viaje trágico de la existencia es la mayor potenciación del devenir en que se encuentran todos los entes. Así, en Filosofía del futuro encontramos una profundización ontológica de lo que en Drama e identidad se descubrió desde el arte como una clave de la existencia y de la cultura histórica contemporáneas. En este devenir lo que aparece y se da produciendo vértigo y asombro como hábitos pasionales del logos es el ser como fenómeno propiamente; no lo que es mero fenómeno y que, en tanto tal, no se distingue entre el conglomerado de lo presente sino lo que presentándose bajo el modo de la singularidad da que pensar.

¿En qué se distingue el fenómeno propiamente en tanto singular de lo meramente individual? ¿Qué cualidad presente en la cosa misma permite distinguir entre lo individual que es meramente siendo y lo singular que es propiamente deviniendo? En el ser singular se encuentra el impulso que lo lleva más allá de la igualdad consigo mismo desbordándose y reproduciéndose en un ser otro en el cual se presenta insistente y diferencialmente la mismidad del ser en variación. Este impulso de diferenciación creativa de sí mismo en sus propias variaciones se nos ofrece como una reiteración del poder del ser.

Al pensar radicalmente al devenir no se destaca sólo la extinción de todo o la iteración de lo igual; el devenir es inmanentemente una potencia física y viva que, en tanto ser del ente, posibilita que éste, como singular propio se recree reiterándose en su diferencia. El ente singular sensible en devenir "es, pues, diferenciable por su poder" ${ }^{16}$

El poder de recrearse es inseparable de la asunción plena de la condición finita y temporal del ente mismo. En su recreación el ser singular tensa su presencia y su presentarse prolongando el pasado constitutivamente antecedente y prolongándose hacia el futuro constitutivamente consecuente. El devenir reúne constitutivamente las dimensiones del tiempo no tanto en lo meramente presente como en lo propiamente presente como descendiente de un poder previo y como ascendiente de un poder posterior. El poder persiste recreándose en el tiempo y el tiempo es devenir real concretizándose en el poder de los entes.

${ }^{16}$ E. Trías, Filosofía del futuro, p. 61. 
Este poder de recreación afirmando la finitud en el hoy apropiándose del pasado y promoviéndose hacia el futuro se manifiesta en el ser humano como memorización y anticipación que se iluminan en la palabra y en el acto que abren la historicidad propia. El poder no carece de obstáculos internos: jalándolo hacia un presunto centro que, coagulándolo, lo desvirtúa, en él hay fuerzas contrarias a la expansión. Estas fuerzas son sombras que, agazapadas en el seno mismo del devenir, pretenden roer toda posibilidad generadora de historia instalándose en la administración de lo que, derivándose del poder, pretende sofocarlo: el dominio.

Una de las constantes fértiles en la meditación de Trías sobre el poder es su preocupación por matizar su relación distintiva con el dominio. El dominio emponzoña al poder al sofrenar a la memoria y al proyecto desde la pretensión de instaurarse y mantenerse en el presente desligado de toda dimensión dinámica con el devenir. Frente a la arrogancia del dominio que, como una máquina, funciona deformando y debilitando todo lo que somete, el poder no sólo resiste, también salvaguarda y persevera en la afirmación de la existencia como ser para la recreación.

La deuda contraída en el nacimiento la afronta la existencia resolviéndose a sí misma en su diferenciación temporal. Esta concepción de la existencia como ser para la recreación es derivada de la constitución ontológica manifiesta en el devenir de lo físico y lo vital, devenir que, pensado radicalmente, permite obtener la idea de variación que soporta a la existencia "jubilosamente afirmada con toda su carga de bondad, de horror y pesadilla". ${ }^{17}$ La existencia como ser para la recreación es la respuesta de Trías al ser para la muerte de Heidegger. Y, en esta respuesta, se hilvanan elementos heredados de Kierkegaard y Nietzsche.

Kierkegaard, con su reflexión sobre el salto sostenida ontológicamente en la categoría de la repetición, y Nietzsche, con su idea de voluntad de poder, proporcionan a Trías el fermento desde el cual él destila su concepción del devenir como movimiento real. La constitución del ser sensible en devenir acontece a saltos en cuya repetición es posible identificar al mismo ser en su renovación. Salto y repetición en el devenir permiten pensar lo nuevo en el tiempo: lo nuevo es lo mismo que se repite a través del salto, diferenciándose respecto al pasado que insiste y disponiendo la anticipación del futuro. Al repetir una acción en el salto, inauguramos una nueva en la que la anterior persiste y en la que la posterior encuentra un antecedente. El salto introduce la diferencia en la repetición transformándola en recreación. Este hilo kierkegaardiano es cruzado con la idea nietzscheana de la voluntad de poder tejiendo una síntesis creadora que posibilita "pensar tiempo e historia desde el futuro" ${ }^{18}$ En el

${ }^{17}$ Cf. ibid., pp. 35-36.

${ }^{18}$ Ibid., p. 40. 
salto, que siempre es hacia delante, lo nuevo se presenta como recreación de lo que ya fue y esto que fue, fue también en su momento recreación diferente de lo que lo precedió. Lo que se afirma en su repetición y diferencia es retorno de un mismo poder: lo que fue se recrea novedosamente al presentarse desde su salto diferencial. Y lo que se revela en este proceso es poder; poder ser como posibilidad de activación que supera su propio pasado, afirma su presente y anticipa y proyecta su futuro. ${ }^{19}$

Desde Nietzsche escribe Trías lo siguiente: "Es el mismo ser sensible en devenir el que se produce y reproduce temporalmente, tiempo son sus arterias y la sangre que corre a través de ellas. Y esa mismidad es conforme con la esencial diferenciación de su esencia. De manera que mismidad y diferencia deben decirse ontológicamente de él". ${ }^{20}$

Frente al dominio que pretende cancelar todo horizonte de futuro, el poder del devenir y el devenir del poder muestran que ningún logro, ninguna meta es definitiva; toda estación a la que arriba la existencia es de tránsito.

La voluntad de poder de Nietzsche es conectada por Trías con la concepción de Platón sobre el carácter productivo o poiético de eros de modo tal que aquella es pensada como retorno de un poder que, memorizado activamente, se repite hacia un futuro que se presiente y anticipa. Y esto que se re-produce o re-crea es repetición diferente de lo mismo que, en el salto, aumenta su propia potencia poiética. ${ }^{21}$ Así se trama la propuesta con la que, en esta estación de su aventura filosófica, Trías responde al problema del devenir y la existencia afirmada en él como ser para la recreación. La capacidad re-creativa del poder y su expresión más transparente - el arte- así como la humanidad y la sociedad en la que ésta se realiza, se convierten en los campos de prueba para el carácter afirmativo de la filosofía.

\section{Humanismo trágico}

Una filosofía asumida conscientemente como afirmativa traza esta distinción suya incluyendo en sí una peculiar concepción del ideal humano sustentado en el carácter problemático de la razón desembocando en un humanismo trágico definido por la contradicción entre el dominio de la realidad y el poder de la libertad.

El ideal no es un escape de la realidad sino una confrontación con ella amparada en la crítica y en las posibilidades que ésta, desde la razón, des-

\footnotetext{
${ }^{19}$ Cf. ibid., pp. 39-40.

${ }^{20}$ Ibid., p. 72.

${ }^{21}$ Cf. ibid., pp. 40-41.
} 
cubre en la propia facticidad. Ideal es, entonces, lo que perseverando en su carácter de tal, sirve para desenmascarar formas concretas de dominación y, a la vez, se mantiene como aspiración orientadora y valoradora del existente en devenir. Por esto, Trías llama al ideal horizonte de poder: toda posición de poder alcanzada por la sombra del dominio es susceptible de ser rebasada por el mismo poder en devenir que no renuncia a proyectar el futuro. El desborde ideal de lo posicionado está guiado por ideas prácticas problemáticas que, en tanto llevan al existente a la afirmación de los impulsos y los hábitos propios, lo ascienden pasionalmente por encima de los laberintos del dominio. "El ideal es siempre horizonte de futuro. Horizonte que se abre como invitación al ente a rebasar su estado y superarse. Es, pues, propiciación de la serie ascensional de las variaciones". ${ }^{22}$

La apertura del futuro la realiza el ideal desde el poder de la libertad y la memoria. Como efecto del ejercicio del poder propio, la libertad es desprendimiento de todo presunto estado definitivo; es derrumbar la estacada que encierra nuestras potencias liberándolas en la construcción propia de modo que el existente consiga "ser a la vez sí mismo siendo diferente". ${ }^{23}$ Y si esto que uno hace lo consigue dejando que otros lo hagan por sí mismos, entonces, la sociedad de hombres libres sobrepasaría las relaciones de dominio procurando por sí mismos y propiciando para otros el devenir y la variación de su existencia temporal y personal.

Una sociedad tal es un horizonte de futuro; un ideal de la razón cuyas fuentes de iniciación histórica las encuentra la memoria en la síntesis de eros y póiesis divisada por el humanismo moderno, tanto en sus potentes raíces renacentistas como en su desarrollo problemático posterior que, comenzado por Goethe, Schiller y Hölderlin, culmina en Marx y Nietzsche.

La buscada síntesis de deseo y producción en el terreno cívico y político lleva a que el ideal exprese una conciencia insatisfecha con la facticidad. Esta carencia, en tanto lucha por solventar realmente la síntesis de eros y póiesis, deviene desgarramiento trágico cuando claramente se constata no sólo su posibilidad sino su necesidad respecto a la verdad del ideal y, con no menos lucidez se comprueba que en el plano fáctico es imposible realizarla tal cual. El humanismo trágico se distingue por afirmar la idea crítica motriz de la síntesis de individuo y género como realización de lo humano universal en el mundo histórico y, junto con esto, por comprobar el carácter enajenado de la facticidad cívica y política en la que el hombre vive dividido, cosificado, extraño en un mundo creado por él mismo. ${ }^{24}$ La filosofía de Marx es, en este

\footnotetext{
22 Ibid., p. 105.

23 Ibid., p. 104.

${ }^{24}$ Cf. ibid., p. 114.
} 
punto, indispensable por su penetración reveladora de la condición humana en la modernidad capitalista.

A la filosofía afirmativa no se le nubla la vista sobre la situación degradada del hombre en la sociedad actual. Y la lucidez con que critica la alienación humana abre la necesidad de superarla rescatando la concepción desbordante de las ideas prácticas respecto a toda facticidad.

La dimensión trágica del humanismo -su desgarramiento consciente entre la realidad sometida al dominio y la posibilidad de superarla por el ejercicio libre del poder propio- vuelve imprescindible atender el doble sentido encerrado en la palabra humanidad. Humanidad se refiere, en un primer sentido, a un ente cuya existencia se da de hecho como materia de inteligencia y pasión. Éste es el modo de ser específico de un ente que, en tanto género, se distingue de cualquier otro ser vivo. Pero humanidad tiene también un significado ético cuya contraposición no se ubica en otros seres de especie o género distintos sino en sí mismo como capacidad de negación de su ser o poder propio. Humanidad, en este segundo sentido, se refiere al modo ético de realización de lo humano en el mundo frente a lo inhumano que, por paradójico que parezca, sólo aparece como realidad desde la acción del propio género humano. Sólo el ser que es materia de inteligencia y pasión puede negar su poder propio ahogando sus pasiones en acciones insensatas.

El parentesco entre los dos sentidos de humanidad se manifiesta porque únicamente el género humano (en sentido fáctico) puede realizar humanidad o inhumanidad (en sentido ético) en el mundo. El ser humano, singularmente y en o contra los otros, en y desde la facticidad, se juega la libertad y el poder en la alternativa entre lo humano y lo inhumano, alternativa que se define como ajuste o desajuste al límite que provee poder al ser que libremente elige. ${ }^{25}$

El humanismo trágico se articula desde una doble oposición en la que sus distintos elementos entran en colisión: la facticidad genérica que se atrofia o supera éticamente eligiendo entre su degradación y su potenciación, y la facticidad social y política que, anhelando estatificar una forma de vida y de valoración de la misma, pretende sofocar la variación que sobre lo humano introduce el ideal a través de la práctica problemática consciente de la imposibilidad de alcanzar o consumar la síntesis de deseo y producción. Afirmar desde las ideas prácticas problemáticas la necesidad de superar la enajenación a través de la experiencia ascensional de la pasión y la inteligencia, sin perder la conciencia de que, por lo que nosotros mismo somos, es imposible alcanzar una sociedad absolutamente libre es, a fin de cuentas, el esfuerzo por potenciarla en el mundo ético, social y político.

${ }^{25}$ Cf. E. Trías, La aventura filosófica. Madrid, Mondadori, 1988, pp. 92-93. 